\title{
A cross sectional study on utilization of postnatal services in rural health training centre, Chandragiri, Andhra Pradesh
}

\author{
Kiranmayi Karanati ${ }^{1 *}$, Ashok Kumar Ready ${ }^{2}$, Pravallika $S^{3}$ \\ ${ }^{1,3}$ Assistant Professor, ${ }^{2}$ Professor, Dept. of Community Medicine, ${ }^{1}$ Mamata Acadamy of Medical Sciences, Hyderabad, Telangana, ${ }^{2}$ Sri \\ Venkateswara Medical College, Tirupathi, Andhra Pradesh, ${ }^{3}$ Narayana Medical College, Nellore, Andhra Pradesh, India
}

*Corresponding Author: Kiranmayi Karanati

Email: kiranmayi.karnati@gmail.com

\begin{abstract}
Introduction: Majority of maternal deaths can be prevented through appropriate maternal health services. According to NHFS-3 postnatal care tends to be low at 36\%, percentage of deliveries with a post natal checkup in India is $41.2 \%$ and in Andhra Pradesh it is $73.3 \%$. Percentage of deliveries with a post natal checkup within 2 days of birth is $37.3 \%$ in India and 64.1\% in Andhra Pradesh. ${ }^{1}$ In developing countries like India; the utilization of basic health services has remained poor.

Materials and Methods: A community based cross sectional study conducted among 211 women at rural health training centre, Chandragiri. Women who had delivered more than six weeks ago (completed puerperal period) and within six months after delivery were included in the study.

Results: The mean age of study subjects was $23.1 \pm 2.1$ years. Of the total study subjects, majority $(90.1 \%)$ were aware about postnatal services and $186(88.2 \%)$ utilized postnatal services.

Conclusion: Knowledge and utilization of post natal services are good in the present study area especially at peripheral level. Health education programmes should be implemented to further increase the utilization.
\end{abstract}

Keywords: Post natal care, Post natal services, Utilization, Maternal health.

\section{Introduction}

Majority of maternal deaths can be prevented through appropriate maternal health services. According to NHFS-3 postnatal care tends to be low at $36 \%$, percentage of deliveries with a post natal checkup in India is $41.2 \%$ and in Andhra Pradesh it is $73.3 \%$. Percentage of deliveries with a post natal checkup within 2 days of birth is $37.3 \%$ in India and $64.1 \%$ in Andhra Pradesh. ${ }^{1}$ In developing countries like India, the utilization of basic health services has remained poor. The reasons for non utilization of maternal health services could be due to various social, cultural, economic factors. Education, birth order and standard of living index also influences in utilization of health services.

Majority of these services are provided at the community level through peripheral health workers. They provide advice, information and basic health services for pregnant women and mothers. The post natal services provided at the community level include counseling on family planning, breast feeding practices, nutrition, early detection of post partum complications, information about existing health services etc. However the presence of health workers in the village, their ability to build on one-to-one relationship with the women in villages and the ability to make home visits give them an advantage over both the formal health care delivery system and traditional health care practices that are still prevalent in India. ${ }^{2}$

Many women who give birth in facilities, are discharged within hours after childbirth, without any indication about where they can obtain further care or support. However, as the utilization of maternal health care ultimately comes down to the community level in which women live, it is of key importance to pay attention to the perspective of the women themselves. ${ }^{3}$ Hence, understanding of these factors at the community level is required. If these factors are correctly identified, then the program efforts can be concentrated to increase the acceptance/utilization rates. Therefore, keeping this in view, this study was conducted to assess the utilization pattern of mothers, the facilitators and the barriers of utilization of services.

\section{Aim and Objectives \\ Aim}

To study the utilization and factors affecting the utilization of postnatal services in Rural Health Training Centre area of Chandragiri.

\section{Objectives}

1. To assess the utilization of postnatal services.

2. To assess the utility of Janani Suraksha Yojana Programme.

3. To determine the socio demographic and health related factors influencing the utilization of postnatal services.

\section{Materials and Methods}

The present study was a community based cross sectional study done at rural health training centre, Chandragiri which is a field practice area of Department of Community Medicine, Sri Venkateswara Medical College, Tirupathi. It has three subcentres namely Chandragiri, Narsingapuram, Dornakambala. Women who had delivered more than six weeks ago (completed puerperal period) and within six months after delivery were included in the study. Sample size was calculated considering the prevalence of utilization of postnatal services of $68 \%,{ }^{4}$ confidence interval $95 \%$ and non response rate of $10 \%$. The obtained sample size was 
189 and this study was done in 211 subjects. Multi stage sampling procedure was used to select the required sample.

Study was conducted for a period of 11 months from October 2014 to August 2015 after obtaining approval from institutional ethical committee and taking informed consent from the study subjects. A pre-designed and pre-tested questionnaire was used to collect data. Data was collected by interviewing the study population by door to door survey. The data was compiled and analyzed using Epi Info version 7.1.4.

Descriptive analysis was done (relative frequency). Chi-square was conducted to study the influence of factors on postnatal services. $\mathrm{p}$ value of $<0.05$ was considered as significant.

\section{Results}

Among the study subjects $59.7 \%$ of them were in the age group of 20-24 years followed by $25-29$ years $(27.5 \%)$. The mean age of study subjects was $23.1 \pm 2.1$ years. Of the total study subjects, majority $(90.1 \%)$ were aware about postnatal services and $186(88.2 \%)$ utilized postnatal services.

Table 1: Place of postnatal service utilization $(n=211)$

\begin{tabular}{|l|c|c|}
\hline Place of postnatal service & Number of subjects (n) & Percentage \\
\hline Service not utilized & 25 & 11.8 \\
\hline Govt. Hospital & 38 & 18.0 \\
\hline Private Hospital & 32 & 15.2 \\
\hline Home(visits by skilled health worker) & 116 & 55.0 \\
\hline Total & 211 & 100.0 \\
\hline
\end{tabular}

Table 1 shows distribution of respondents according to source of postnatal service utilization. Majority of study subjects (62.4\%) utilized postnatal services at home by skilled health worker followed by hospitals (Government and private hospitals) which is $37.6 \%$. Of the study subjects $53.5 \%$ had less than 3 postnatal visits. Only $34.6 \%$ mothers had three or more than three postnatal visits.

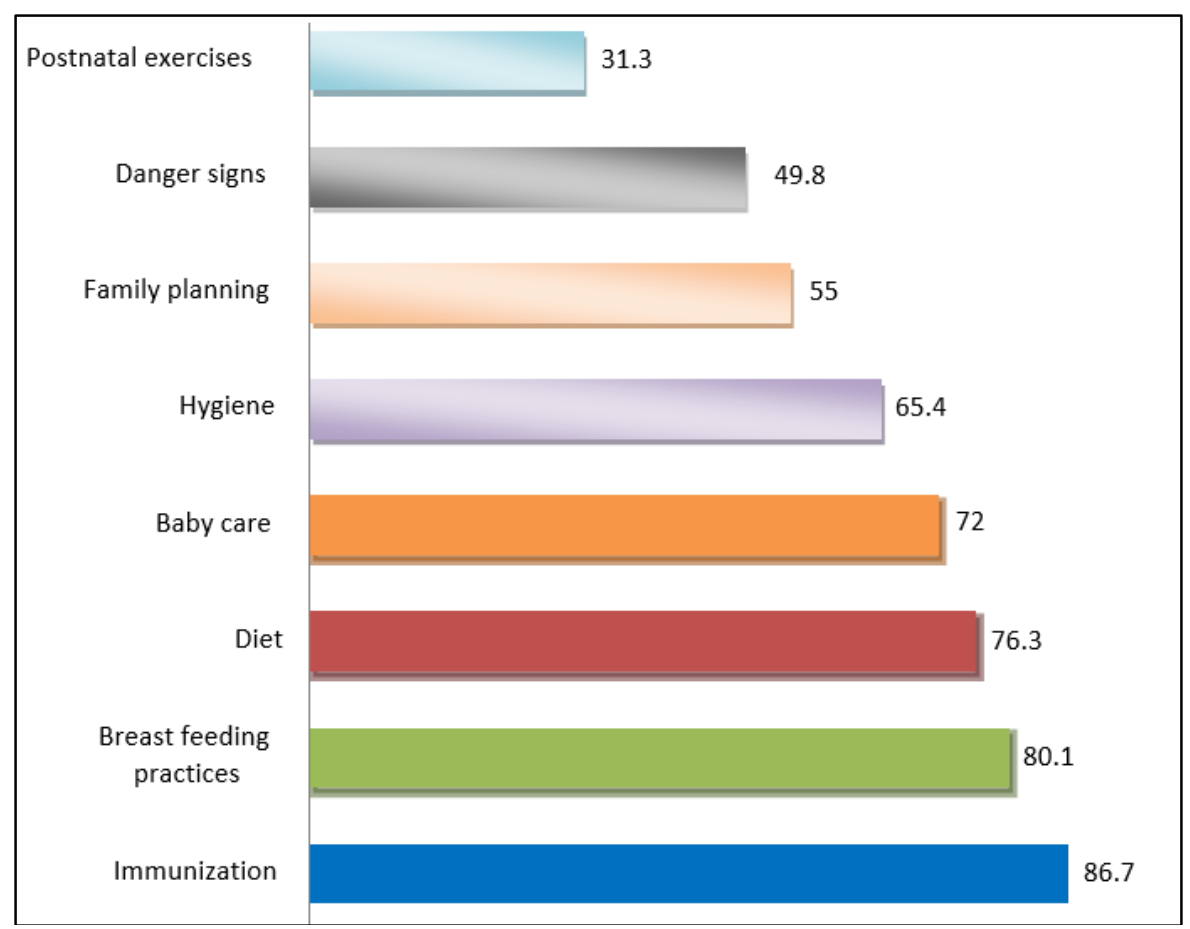

Fig. 1: Distribution of study subjects regarding postnatal advise given by health worker(n=211)

In the study it was observed that $86.7 \%$ of mothers received advice regarding immunization $80.1 \%$ about breast feeding practices, $76.3 \%$ about nutrition and $72.0 \%$ about baby care. Counseling for hygiene was given to $65.4 \%$ of the mothers and advice on postpartum complications was given to $49.8 \%$ of mothers. Advice about postnatal exercises and family planning was given to $31.3 \%$ and $55 \%$ of the mothers respectively.

Role of ASHA worker in mediation of health worker and beneficiary was satisfactory and rapport among beneficiary and community found to be satisfactory. 
Table 2: Utilization of postnatal services in relation to parity

\begin{tabular}{|l|c|c|c|}
\hline Parity & $\begin{array}{c}\text { Utilized postnatal services } \\
\mathbf{n}(\mathbf{\%})\end{array}$ & $\begin{array}{c}\text { Not utilized } \\
\mathbf{n}(\boldsymbol{\%})\end{array}$ & $\begin{array}{c}\text { Total } \\
\mathbf{n}(\boldsymbol{\%})\end{array}$ \\
\hline Primipara & $139(92.1 \%)$ & $12(7.9 \%)$ & $151(100.0 \%)$ \\
\hline Multipara & $47(78.3 \%)$ & $13(21.7 \%)$ & $60(100.0 \%)$ \\
\hline Total & $186(88.2 \%)$ & $25(11.8 \%)$ & $211(100.0 \%)$ \\
\hline
\end{tabular}

$\chi^{2}=7.74 ; d f=1 ; p=0.005 ; S$

As the birth order increases the probability of utilizing postnatal services was decreased.

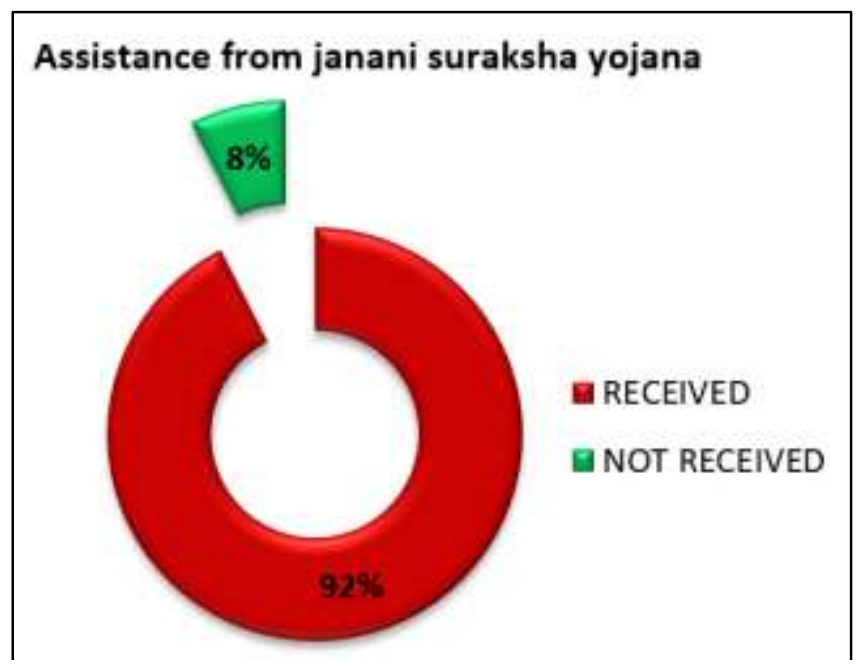

Fig. 2: Percentage of mothers received assistance from Janani Suraksha Yojana

Out of 211 mothers only 134 were eligible for JSY. Of the total number of eligible women, $92 \%$ of mothers had utilized the scheme. Only $8 \%$ of mothers had not utilized the scheme.

Table 3: Utilization of postnatal services in relation to socio demographic factors $(n=211)$

\begin{tabular}{|c|c|c|c|c|}
\hline \multirow[t]{2}{*}{ Variables } & \multicolumn{2}{|c|}{ Postnatal services } & \multirow{2}{*}{$\begin{array}{l}\text { Total } \\
\text { n }(\%)\end{array}$} & \multirow[t]{2}{*}{ Statistical significance } \\
\hline & $\begin{array}{c}\text { Utilized } \\
\text { n }(\%)\end{array}$ & $\begin{array}{l}\text { Not utilized } \\
\text { n }(\%)\end{array}$ & & \\
\hline \multicolumn{3}{|l|}{ Age group (Years) } & & \multirow{5}{*}{$\begin{array}{c}\chi^{2}=2.4 ; \mathrm{df}=2 ; \mathrm{p} \text {-value }= \\
0.30\end{array}$} \\
\hline $15-19$ & $14(77.8)$ & $4(22.2)$ & $18(100.0)$ & \\
\hline $20-24$ & $111(88.1)$ & 15(11.9) & $126(100.0)$ & \\
\hline 25 and above & $61(91.0)$ & $6(9.0)$ & $67(100.0)$ & \\
\hline Total & $186(88.2)$ & $25(11.8)$ & $211(100.0)$ & \\
\hline \multicolumn{4}{|l|}{ Social class } & \multirow{5}{*}{$\begin{array}{c}\chi^{2}=1.6 ; \mathrm{df}=2 ; \mathrm{p} \text {-value }= \\
0.44\end{array}$} \\
\hline Other caste & $65(89.0)$ & $8(11.0)$ & $73(100.0)$ & \\
\hline Backward caste & $62(91.2)$ & $6(8.8)$ & $68(100.0)$ & \\
\hline $\begin{array}{l}\text { Scheduled caste/ Scheduled } \\
\text { tribe }\end{array}$ & $59(84.3)$ & $11(15.7)$ & $70(100.0)$ & \\
\hline Total & $186(88.2)$ & $25(11.8)$ & $211(100.0)$ & \\
\hline \multicolumn{4}{|l|}{ Education of subject } & \multirow{6}{*}{$\begin{array}{c}\chi^{2}=1.37 ; \mathrm{df}=3 ; \mathrm{p} \text {-value }= \\
0.71\end{array}$} \\
\hline Illiterates & $21(87.5)$ & $3(12.5)$ & $24(100.0)$ & \\
\hline Middle School & $27(87.1)$ & $4(12.9)$ & $31(100.0)$ & \\
\hline High School & $58(92.1)$ & $5(7.9)$ & $63(100.0)$ & \\
\hline College & $80(86.0)$ & $13(14.0)$ & $93(100.0)$ & \\
\hline Total & $186(88.2)$ & $25(11.8)$ & $211(100.0)$ & \\
\hline \multicolumn{4}{|l|}{ Socio economic status } & \multirow{4}{*}{$\begin{array}{c}2 \\
\chi=5.33 ; \\
\mathrm{df}=1 ; p \text {-value }=0.021\end{array}$} \\
\hline Below middle class & $67(81.7)$ & $15(18.3)$ & $82(100.0)$ & \\
\hline middle class and above & $119(92.2)$ & $10(7.8)$ & $129(100.0)$ & \\
\hline Total & $186(88.2)$ & $25(11.8)$ & $211(100.0)$ & \\
\hline
\end{tabular}




\section{Discussion}

Among the study population $88.2 \%$ of the mothers received postnatal service and $11.8 \%$ mothers didn't receive the postnatal service. Similarly a study done by Paudel et al., in Belgam $^{5}$ found that $79 \%$ mothers had utilized the postnatal service. The present study findings were in disagreement with a study done by Rudramma ${ }^{6}$ in Belgaum of Karnataka in which $46.7 \%$ mothers did not receive postnatal care service. Another study conducted by Swapna et al., ${ }^{7}$ found that $15 \%$ mothers did not receive any postnatal service.

In the present study $62.4 \%$ subjects utilized postnatal services at home by skilled health worker, $20.4 \%$ respondents utilized postnatal services at government institution, $17.2 \%$ respondents utilized postnatal services at private institution. While in a study done by Srivastava et al., ${ }^{8}$ found that $53.2 \%$ respondents availed postnatal services at government hospital, $24.5 \%$ from private hospital and $22.3 \%$ at home by health worker. Study done in Andhra Pradesh $^{7}$ revealed $39.3 \%$ availed postnatal services from government hospital and $46 \%$ from private hospital.

In the study it was observed that $80.1 \%$ of the mothers had received advice regarding breast feeding practices, $72.0 \%$ about baby care, $86.7 \%$ received regarding immunization and $76.3 \%$ about nutrition. Counseling for hygiene was given to $65.4 \%$ of the mothers and advice on postpartum complications was given to $49.8 \%$ of mothers. Advice about postnatal exercises and family planning was given to $31.3 \%$ and $55 \%$ of the mothers respectively.

Study done by Paudel, et al., ${ }^{5}$ found that $92.5 \%$ received advise about breast feeding, $67.9 \%$ about postnatal exercise, $89.0 \%$ nutrition education, $71.7 \%$ were told about family planning, $84.9 \%$ had received advise on postnatal complication.

Agarwal et al., ${ }^{9}$ study reported that advice regarding family planning, breast feeding and baby care was provided in $29.8 \%, 71 \%$ and $59 \%$ respectively. The present study findings were similar to above study with regard to breast feeding.

Maximum utilization of postnatal services was observed among mothers in age group of 25 years and above $(91.0 \%)$, mothers $(91.2 \%)$ from backward caste, mothers who had completed high school education (92.1) and middle class and above socio economic status women $(92.2 \%)$. While a study done by Paudel, ${ }^{5}$ et al found that postnatal service utilization was more likely among mothers in age group of 20-35 years(79.1\%), those who had some schooling $(80 \%)$, whose income is less than $3000(87.4 \%)$ and Bhaisare et al., ${ }^{10}$ study in Maharashtra revealed that (81.2\%) mothers, who utilized PNC services were literates.(p>0.05), were from lower socio economic class.( $p$ $<0.05)$

Sharma et al., ${ }^{11}$ study observed that, education of mothers $(\mathrm{p}=0.003)$ was important contributing factor with utilization of postnatal care $(\mathrm{OR}=2.545$; 95\% CI:1.3754.714). Mothers who belonged to other caste utilized PNC 3.421 times more (95\% CI:1.691-6.921) $(\mathrm{p}=0.000)$. The study also showed mothers aged 15-24 years $(\mathrm{p}=0.064)$, mothers from lower socio economic class $(\mathrm{p}=0.094)$ were more likely to utilize postnatal services. Level of education showed strong statistical association with postnatal care service utilization in a study done in Ethiopia. ${ }^{12}$ Mothers who attended secondary school were about 4 times (AOR=4.16, 95\% CL:(2.48, 8.71) more likely to utilize postnatal care service than illiterate women.

\section{Conclusion}

Knowledge and utilization of post natal services are good in the present study especially at peripheral level. They were influenced by Parity, literacy and socio economic status of postnatal women. Health education programmes should be implemented to further increase the utilization at all levels.

\section{Source of Funding}

None.

\section{Conflict of Interest}

None.

\section{References}

1. International Institute for Population Sciences (IIPS) and Macro International. 2007. National Family Health Survey (NFHS-3), 2005-06: India: Volume I. Mumbai: IIPS.

2. Shariff A, Singh G. Determinants of Maternal Health Care Utilisation in India: Evidence from a Recent Household Survey. National Council of Applied Economic Research, February 2002. Working Paper Series No.85. [cited 2015 Aug 31]; Available from: www.ncaer.org.

3. WHO 2013: Programming Strategies for Postpartum Family Planning. [cited 2015 Aug 31]; apps.who.int/iris/bitstream/10665/93680/1/9789241506496_en g.pdf

4. International Institute for Population Sciences (IIPS) and Macro International. 2007. District Level Household and Facility Survey(DLHS3),2007-08: India: Volume I. Mumbai: IIPS.

5. Paudel DP, Nilgar B, Bhandankar M. Determinants of postnatal maternity care service utilization in rural Belgaum of Karnataka, India: A community based cross-sectional study. Int J Med Public Health. 2014;4:96-101.

6. Rudramma. Utilization of antenatal, intranatal and postnatal health care services by mothers in Rural field practice area of JNMC, Belgaum. A cross sectional study [dissertation]: K.L.E. University, India; 2010.

7. Swapna B, Kalyan C. Utilisation of maternal health care services in slums of east Godavari district of Andhra Pradesh. Int J Med Health Sci. 2013;2(2):141-8.

8. Srivastava AK, Kishore S, Padda P. Socio economic differentials in utilization of maternal health care services: A study in urban slums of District Dehradun. Bangladesh J Med Sci. 2015;14(3):280-5.

9. Agarwal N, Galhotra A, Swami HM. A study on coverage utilization and quality of maternal care services. Natl J Community Med. 2011;2(1):32-6.

10. Bhaisare KA, Khakase GM. Study of utilization of postnatal care services in tribal area, Maharashtra. Int J Med Sci Public Health. 2014;3:1487-91.

11. Sharma A, Thakur PS, Kasar PK, Tiwari R, Sharma R. Utilization of post natal care in tribal area of Madhya Pradesh: A community based cross sectional study. Int J Med Sci Public Health. 2014;3:1266-71. 
12. Workineh YG, Hailu DA. Factors affecting utilization of postnatal care service in Jabitena district, Amhara region, Ethiopia. Sci J Public Health. 2014;2(3):169-76.

How to cite this article: Karanati $\mathrm{K}$, Ready $\mathrm{AK}$, Pravallika S. A cross sectional study on utilization of postnatal services in rural health training centre, Chandragiri, Andhra Pradesh. Indian $J$ Forensic Community Med. 2020;7(1):24-8. 